REVISTA CHILENA DE LITERATURA

Abril 2010, Número 76, 237 - 256

\title{
EL ORIGEN DE UN TÓPICO LITERARIO: TRADICIÓN Y VANGUARDIA EN LA GENERACIÓN DEL 27
}

\author{
Isabel Navas Ocaña \\ Universidad de Almería \\ minavas@ual.es
}

PAlABRAs ClaVE: crítica literaria, literatura española contemporánea, generación del 27, vanguardias, poesía española de posguerra.

KEY WORDS: Literary critics, Spanish Contemporary Literature, Generation of '27, Post Civil War Spanish Poetry.

\section{INTRODUCCIÓN}

En casi todos los acercamientos críticos a la poesía de la generación del 27 está presente esa conjunción, hoy ya tópica, entre tradición y vanguardia ${ }^{1}$. Resultaría difícil concebir, sin ella, la obra de Gerardo Diego, la de Aleixandre, la de Lorca o la de Alberti, tan numerosos

1 Valga como muestra la edición que Andrés Soria Olmedo publicó en 1991 de las famosas antologías de Gerardo Diego (1932 y 1934). Cuando se refiere a "los dos principales actos colectivos del grupo" (el homenaje a Góngora y las antologías), Soria dice que "en ambos los modos de la vanguardia (constituyen un grupo cerrado, juegan como los dadaístas, emprenden actos agresivos contra las instituciones oficiales (Academia) como los futuristas), se ponen al servicio del orden, de la tradición renovada" (30). Y cuando analiza los poemas de Gerardo Diego, Lorca y Alberti, hace los siguientes comentarios: Gerardo Diego "inserta las audacias expresivas de la vanguardia en las sextinas reales de un pastiche gongorino ("Fábula de Equis y Zeda") y ejerce su maestría en moldes populares (seguidillas) y cultos (sonetos), cuyo clasicismo nada tiene de arcaico, al ser visible únicamente como término opositivo a su propia "poesía de creación"” (18). Con Lorca "la formación modernista y vanguardista abre paso al diálogo con la tradición, culta y sobre todo popular" (18). Y en Alberti "igualmente puede observarse un juego paralelo de tradición y vanguardia" (19). 
son los estudios que han insistido en el tema desde fecha temprana ${ }^{2}$. Podríamos decir que este concepto ha calado profundamente en la crítica literaria española contemporánea. Y desde este ámbito especializado ha sido exportado a otros relacionados con él: la docencia, el periodismo, etc. En cualquier manual de literatura española, incluso en los más elementales, la tradición y la modernidad de los poetas del 27 es un hecho aceptado sin discusiones, que determina la primera aproximación del estudiante a la poesía de esta generación ${ }^{3}$. Igual ocurre con artículos periodísticos, menciones televisivas, etc. Es ya prácticamente imposible disociar la poesía del 27 del marbete de tradicionalismo y vanguardismo, como tampoco podemos separar la figura de James Dean del prototipo de joven rebelde o la de Penélope de la esposa ejemplar.

Además, a esta generación se la suele considerar una de las más valiosas de la literatura española ${ }^{4}$. Por eso, el marbete va a funcionar como patrón para futuras promociones. Adquirirá así un estatus singular que presenta caracteres casi de mito, puesto que se convierte en un sistema de valores, capaz por sí mismo de generar modelos, en este caso literarios, de gran impacto. Pero ¿cuáles son esos modelos? La conciliación de tradición y vanguardia parece sugerir la imagen ejemplar de la mesura, del perfecto equilibrio, de la armonía ideal. Y presupone en el artista una importante cantidad de información erudita, que le permita no solo innovar sino a su vez trasplantar esos hallazgos a la corriente de lo tradicional ${ }^{5}$. Gerardo Diego dio abundantes muestras de ello al encerrar imágenes creacionistas en moldes clásicos (Soria 18). Se ha hablado también con insistencia del carácter profesoral de muchos miembros de la generación del $27^{6}$.

2 Quizás el caso de Gerardo Diego sea el más llamativo. Podrían citarse como ejemplo los trabajos de Gianfranco di Stefano (1974), Rafael Espejo-Saavedra (1982) y Carlos Bousoño (1988).

3 Se puede consultar, por ejemplo, el manual de C.O.U. de la editorial Anaya, La Literatura del siglo $X X$, de Vicente Tusón y Fernando Lázaro.

4 No en vano se ha hablado para referirse a ella de un nuevo Siglo de Oro. Así lo hizo Dámaso Alonso en 1948: "Hay que ir al Siglo de Oro y pasar por alto allí mucha rutina, mucho culto a la forma externa; sí, hay que ir al Siglo de Oro, y precisamente allá por los años 1580 y tantos, cuando fray Luis y San Juan de la Cruz viven aún y Góngora y Lope son jóvenes; sí, hay que ir a esos años del Siglo de Oro, para encontrar algo semejante a la confluencia de generaciones poéticas en la que hemos vivido" ("Una generación” 191).

5 El espadañista Antonio González de Lama definió muy pronto (1944) la faceta erudita de la generación del 27, a partir de dos aspectos: una erudición que se vuelca hacia el pasado (el Siglo de Oro, Góngora, nuestra poesía tradicional) y otra que se dirige a la actualidad (los movimientos de vanguardia). Es el primero, por tanto, que trata este aspecto, el erudito, del tópico tradición y vanguardia ("La nueva poesía de Dámaso Alonso").

6 José Francisco Cirre, en una de las primeras monografías dedicadas al 27 como grupo, Forma y espíritu de una lírica española (1920-1935) (1950), dice: "Conviene recordar que los iniciadores del movimiento renovador -Salinas, Valbuena Prat, Jorge Guillén, Dámaso Alonso, Mauricio Bacarisse, etc.- no son, en su mayoría gentes cualesquiera, gentes de la calle. Por el contrario, nos hallamos ante verdaderos "clérigos", en el sentido medieval de la 
Por otra parte, los impulsos artísticos más subversivos dejan de serlo, reinterpretados siempre a la luz de la tradición. En este sentido quizás el tópico se convierte en emblema de esa llamada "tradición de la vanguardia", tan relevante en la cultura postmoderna y que José Luis Bernal, por ejemplo, utiliza para el caso de Gerardo Diego (126). Pero evidentemente puede haber muchas lecturas de este tópico y las seguirá habiendo. Por eso, habría que preguntarse en qué circunstancias surge, a quién o a quiénes se debe su autoría, es decir, habría que estudiar el significado del tópico en su período de formación. Al menos conseguiríamos establecer un punto de partida. Y este punto de partida nos sitúa en un período particularmente conflictivo y difícil: los años cuarenta, la primera posguerra.

Garcilasismo y neorromanticismo fueron las propuestas estéticas que gozaron entonces de mayor fortuna. La primera, el garcilasismo, se puede definir a grandes rasgos por el empleo normativo de la métrica clásica y por el sometimiento de la actividad artística a las consignas del nuevo Estado franquista y del catolicismo. En cambio, la estética neorromántica, que quiso reaccionar firmemente contra estas prerrogativas, favoreció la utilización del verso libre y proclamó la necesidad de expresión individual, sin cortapisas procedentes de la política o de la religión ${ }^{7}$. Pues bien, a partir de estos presupuestos se empieza a fraguar el tópico de la tradición y la vanguardia en los poetas del 27. Veamos de qué forma.

\section{EN EL ORIGEN DEL TÓPICO: GERARDO DIEGO}

Desde fecha temprana, el propio Gerardo Diego apostaba ya por la conciliación de tradición y vanguardia. José Luis Bernal cita a este respecto un "Intencionario" de 1920,

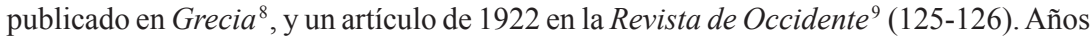
después, ya en 1941, cuando ve la luz la Primera antología de sus versos, Gerardo Diego vuelve a insistir en el tema, ahora para definir su trayectoria poética:

palabra. Intelectuales y eruditos. Profesores universitarios. Individuos colocados al margen de la masa y muy versados en los arcanos de la gaya ciencia. Conocedores y gustadores de ella como tratadistas y críticos" (46). Dos antólogos de la poesía del 27, Ángel González y Vicente Gaos, también se han referido a este hecho (González 15 y Gaos 21-22).

7 Puede consultarse al respecto tanto la tesis doctoral de S. Wahnón (1988) como mis trabajos sobre el grupo escorialista, la llamada "Quinta del 42" y los espadañistas.

8 Dice aquí Gerardo Diego: "Se puede ser ultraísta y saber historia y admirar a Boileau y hasta al P. Alberto Lista... El arte tradicional no ha muerto; seguirá evolucionando... Es más: el mismo artista puede simultanear el arte nuevo y el antiguo (ejemplo Picasso), y hasta tal vez le convenga" (Cit. en Bernal 125-126).

9 "Para reanudar la tradición no es necesario el salto atrás. No podemos renunciar a una sola de las conquistas de expresión que lograron sucesivamente románticos, simbolistas y los diversos futurismos del ayer inmediato" (Cit. en Bernal 132). 
Yo no soy responsable de que me atraigan simultáneamente el campo y la ciudad, la tradición y el futuro; de que me encante el arte nuevo y me extasíe el antiguo; de que me vuelva loco la retórica hecha, y me torne más loco el capricho de volver a hacérmela -nueva- para mi uso particular e intransferible... Todas estas inquietudes se reducen en mí a dos únicas intenciones. La de una poesía relativa, esto es, directamente apoyada en la realidad, y la de una poesía absoluta o de tendencia a lo absoluto, esto es, apoyada en sí misma, autónoma frente al universo real del que sólo en segundo grado procede (15).

Pero es Dámaso Alonso quien contribuyó de forma más eficaz a la creación y al definitivo establecimiento del tópico. En este sentido, resulta emblemático un artículo sobre Alondra de verdad que publicó en 1943 en la revista Escorial. Dos años antes, también en Escorial, José María de Cossío, a partir de la férrea disciplina garcilasista, se mostraba incapaz de aceptar la faceta creacionista de Gerardo Diego, que solo fue, en su opinión, un pecado de juventud, expiado con creces por el santanderino en su nueva y definitiva poesía tradicional, modélica para los intereses del garcilasismo por la utilización de estrofas clásicas, por la temática religiosa, etc. (Navas, Vanguardias y crítica 84-86). Según Dámaso Alonso, sin embargo, hay una unidad esencial entre la vertiente tradicional y la creacionista, ya que ambas brotan "humanamente del corazón apasionado del poeta" (121). El predominio de los valores individuales, que caracterizó a la estética neorromántica, hace aquí su aparición. Gracias a estos valores individuales, Dámaso Alonso no tiene que rechazar una parte de la poesía de Diego, la vanguardista, porque, al igual que la tradicional, no es sino muestra del genio poético de su autor ${ }^{10}$. Sin embargo, el neorromanticismo de Dámaso Alonso mantiene aún un cierto grado de dependencia de la, hasta entonces hegemónica, estética garcilasista. Téngase en cuenta que esta hegemonía se extiende desde el inicio de la década hasta aproximadamente 1943. Pues bien, esa dependencia se observa en la justificación de corte religioso que Dámaso Alonso ofrece de sus teorías: "Cantate Dominum canticum novum. ¡Cantad, poetas, cantad siempre un nuevo cántico al Señor! A la bella variedad del mundo ha de corresponder la bella variedad del arte" (121). Y, sobre todo, podemos advertirla en la conclusión final que plantea sobre la trayectoria poética de Gerardo Diego. Con la frase "también por las rebeldías se llega a lo clásico" (122) se entenderá en qué consiste la lectura de Dámaso Alonso. Su objetivo es demostrar que la vanguardia -y, en particular, las experiencias vanguardistas de la generación del 27-resulta completamente inofensiva para el desarrollo del arte clásico: así lo prueba la poesía de Gerardo Diego que, tras la aventura creacionista, se ha resuelto en la fisonomía tradicional de Alondra de verdad ${ }^{11}$,

10 "Se me dirá: pocas poéticas más movidas o variadas que la suya. No: acercaos. En el fondo, siempre la misma honradez, la misma candidez de intenso, ingenuo y sabio artífice. En el fondo, su única vena inspiradora. En la superficie, la variación. Y en la variación está el gusto" (Navas, Vanguardias y crítica 120).

11 “(...) bien están, necesarios han sido los atrevimientos modernos en busca de una poesía absoluta. De estos generosos intentos mucho se filtra al grande, eterno caudal. Pero 
y así lo prueban también los jóvenes poetas españoles -Rosales, Vivanco, etc.- que, tras la proliferación de "ismos" en las décadas anteriores, han optado por colocarse bajo la advocación de nuestros clásicos Siglos de Oro:

Tras tantos vendavales, una nueva generación poética escribe hoy con clásica tersura, con una impecable suavidad de mano. En las formas abiertas y libres apenas si se puede señalar más que ese magnífico intento que es el Tiempo de dolor, de Luis Felipe Vivanco, y, luego, siempre apartado, señero - honda vena nunca domada- el gran poeta Vicente Aleixandre. Pero, a través de muchos filtros, y aun a veces por capilaridad, materia de aquellos atrevimientos, que ya podemos llamar de antaño, ha pasado hasta la técnica de los más perfectos, la de un Dionisio Ridruejo o la de un Luis Rosales. Sí, también por las rebeldías se llega a lo clásico (122).

En realidad, este planteamiento es una concesión al modelo estético imperante en 1943, el garcilasista.

Un año más tarde, otro destacado representante de la estética neorromántica, el espadañista Antonio González de Lama, insistirá también en la doble faceta de Gerardo Diego:

Se ha hablado mucho -el mismo poeta habla de ello a menudo- de un Gerardo Diego partido en dos, de un poeta de doble faz, mirando al pasado, a la tradición y lanzándose por entre las zarzas de los caminos nuevos. Es el mismo caso de Góngora, con la diferencia de que en Gerardo Diego aparece la dualidad desde sus primeros pasos. Sin embargo, lo mismo que Dámaso Alonso demostró la irrealidad de este dualismo en Góngora, también podría demostrarse cómo en Gerardo Diego los dos caminos son sólo uno. La personalidad del poeta está neta, inconfundible en los poemas de una y otra dirección. Y sería muy fácil espigar elementos creacionistas en el manojo de versos tradicionales y elementos tradicionales en los poemas de novedad más desatada. Puede decirse que hay en éstos acumulación o condensación de rasgos que en los otros estaban desperdigados. De todos modos, no hay que olvidar que Gerardo Diego es un poeta empapado en cultura poética española y, aun cuando algunas veces pretenda libertarse de ella, le sigue siempre enredando entre sus mallas irrompibles. Esta fusión de moderno y antiguo, de nuevo y tradicional, de arbitrariedad y norma, da a la poesía del santanderino un encanto característico ("La poesía de Gerardo Diego").

Pero ahora la situación es diferente, sobre todo después de la batalla librada contra el garcilasismo por la revista Cisneros (Presa 73-103), de la conversión de los escorialistas al neorromanticismo (Navas, Vanguardias y critica 40-43) y del surgimiento de revistas como Espadaña, Corcel o Proel, exponentes de la nueva sensibilidad. Por eso, en este momento González de Lama no tiene que hacer ninguna concesión a una estética, la garcilasista, que iba cayendo en un absoluto descrédito. Y por eso, sus tesis sobre la

mover bellamente, ennoblecer o despertar lo más puro de miles y miles de seres, ésa sí que es Alondra de Verdad, poesía real y a la par absoluta. Como esta Alondra" (141). 
poesía de Gerardo Diego tienen una lógica mayor que las de Dámaso Alonso. Decir que vanguardia y tradición son dos caras de una misma moneda, que ambas tienen su origen en el humanismo de Gerardo Diego, pero que la primera ha ido desapareciendo gradualmente en favor de la segunda, es bastante más intrincado, menos lógico que decir simplemente que la vanguardia y la tradición forman parte de todos y cada uno de los libros de Gerardo Diego, tal como hizo González de Lama:

La esencial unidad de ambas tendencias va siendo más patente a medida que el poeta madura y adquiere dominio de todas sus riendas. Los pasos alborotados y desunidos se van remansando y la poesía se muestra clara y neta como si no estuviera hecha de opuestos ingredientes. Así es cada vez más difícil encasillar sus libros en una de sus dos caras. Algunos sonetos de "Alondra de verdad" alcanzan una fusión tan íntima que semejan la convergencia final de dos ríos en los meandros sosegados y transparentes de la llanura. Y dan pábulo a la idea de que quizá en esa fusión está el remate y madurez de este poeta, ya tan cercano a la perfección ("La poesía de Gerardo Diego").

Pero cuando en 1949 González de Lama publique una reseña de Soria, cuya segunda edición había aparecido en 1948, de nuevo las circunstancias habrán cambiado. Para esta fecha el garcilasismo está definitivamente superado. Sin embargo, otras empresas culturales parecen poner en peligro la hegemonía neorromántica: ante todo la poesía pura que los críticos de Insula pretendieron recuperar en 1948 con el homenaje a Jorge Guillén (Wahnón, Estética y crítica 705-735), pero también la proliferación de nuevos movimientos de vanguardia, como el introvertismo alicantino ${ }^{12}$, sin olvidar que los postistas no estaban inactivos, a pesar de la desaparición de sus revistas ${ }^{13}$. Lama realizará entonces la misma lectura del creacionismo que llevó a cabo Dámaso Alonso en 1943: la vanguardia nunca consigue detener el progreso del arte clásico. El creacionismo es en Gerardo Diego simplemente una "escapada", que concluye siempre con la vuelta a los cauces de la tradición. Incluso en los versos creacionistas se puede advertir la pervivencia del poeta tradicional:

La poesía de Gerardo Diego, variada y cumplida, está pidiendo ya un estudio total y calificativo; (...) En un estudio así, se vería cómo en Gerardo Diego, por debajo de todas sus piruetas, hay un poeta de índole tradicional que habría que entroncar directamente con los poetas barrocos de nuestro siglo XVII; las evasiones al creacionismo o a cualquier otro "ismo" son sólo evasiones, huidas de lo cotidiano y esencial para volver luego al cauce habitual y auténtico. Y aún en esas evasiones queda el mismo Gerardo Diego nutrido de lecturas clásicas, o mejor, barrocas ("Soria de Gerardo Diego").

12 Su primer texto teórico, "La introversión o el bonito juego de la vida", de José Albi, se publicó en el número 14 de la revista Verbo, correspondiente a enero-febrero de 1949.

13 En 1949, Ángel Crespo y Carlos Edmundo de Ory quisieron mantener vivo el fuego del postismo, utilizando como órgano de expresión el periódico Lanza de Ciudad Real (Navas, El movimiento postista 95-108). 
Si esta interpretación era en Dámaso Alonso una concesión a los cánones estéticos del modelo garcilasista, en González de Lama es una recuperación de lo mejor de este modelo - Gerardo Diego- por parte del neorromanticismo, una vez que ha desaparecido la efervescencia antigarcilasista. El neorromanticismo absorbe finalmente al que fue su oponente más destacado, pero continúa mostrándose incapaz de aceptar la vanguardia.

Un ejemplo más de esta absorción lo hallamos en otro espadañista, Eugenio G. de Nora (1948), que pretende desbaratar la imagen dual de Gerardo Diego, concluyendo que la orientación clásica es la que define la creación total del poeta:

El contenido humano controlado, resuelto armónicamente en arte; el equilibrio que de aquí trasciende a la forma, la consciencia artística, la sensación que el poeta da de dominio propio y sobre los elementos que maneja; todo eso que son los caracteres del clasicismo, lo tiene Gerardo Diego incluso en su poesía creacionista. Por eso cabe, si prescindimos de sus tanteos juveniles, decir de él que tiende espontánea y permanentemente al clasicismo (147).

De nuevo, en esa fórmula conciliadora de tradición y vanguardia es esta última la que acaba perdiendo su identidad para servir a los intereses de aquélla. Nora coincide, por tanto, con Dámaso Alonso y con González de Lama: la dualidad de Gerardo Diego se resuelve siempre en el privilegio de la faceta tradicional. No obstante, el proceso mediante el cual Nora llega a semejante conclusión no es el mismo que siguieron Dámaso Alonso o González de Lama. Para estos dos críticos, el creacionismo se limitó a ser una experiencia enriquecedora que no estorbó la esencial clasicidad de Gerardo Diego. Nora, sin embargo, elabora un catálogo de rasgos clásicos - "racionalidad", control intelectual, preocupación por la forma, etc.- y con él se dispone a establecer coincidencias entre nuestro Siglo de Oro (Góngora) y el creacionismo ${ }^{14}$. Retoma así una práctica muy habitual en la crítica española contemporánea: la atribución de un perfil clásico a la vanguardia. Esta práctica se puede datar en los años inmediatamente anteriores a la guerra civil, con protagonistas de la talla de Ortega y Gasset, Guillermo de Torre, Rafael Cansinos Assens, etc. (Navas, Espadaña y las vanguardias 28-50). Por tanto, si, según Dámaso Alonso y González de Lama, Gerardo Diego es un poeta clásico a pesar del creacionismo, según Nora, lo es, en efecto, pero incluso en los versos creacionistas.

De todo esto se obtiene una conclusión fundamental: ese tópico de la faceta tradicional y la vanguardista de Gerardo Diego, y, en general, de la tradición y la vanguardia en

14 "Y es que tanto la tradición española anterior al romanticismo como la actualidad creacionista (de raíces francesas y con un propósito inteligente y reflexivo de alcanzar la obra pura, absoluta), coinciden en la racionalidad, en la justeza intelectual, en la impecabilidad teórica de sus soluciones artísticas. No tiene nada de extraño que la conclusión poética de una corriente cultural francesa -a gran bulto, racionalista, cartesiana, paralela a la madurez de Valéry-, y a la sombra lúcida y severa de Góngora y todo nuestro siglo de oro, en conjunto, vinieran a completarse y fundirse en el temperamento de un poeta ávido de precisión y de nitidez estética" (148). 
la generación del 27 , es una fórmula de compromiso creada en los años cuarenta para atenuar el impacto de la vanguardia, para adaptar las brillantes, aunque heterodoxas, experiencias artísticas de esa generación a la normativa estética de la posguerra. Se trata de una fórmula en la que la vanguardia sale casi siempre malparada, no es equitativa como aparentemente se pretende. No obstante, hubo algunas excepciones, algunas tentativas de presentar equilibradamente la dualidad de Gerardo Diego. Así lo hizo Pedro Salinas en un trabajo titulado "Gerardo de Diego", escrito en los años treinta y publicado luego, ya en la posguerra, en Proel (Navas, La "Quinta del 42" 75-78). Merece la pena transcribir algunos párrafos de este texto:

Es un fanático de la causa. La causa es siempre la poesía. La muy antigua o la muy moderna, la de Soto de Rojas o la de Huidobro, la de Lope o la de Juan Larrea. El elemento peligroso. Agitador. Si hubiera una Guardia civil para la seguridad y protección de las Letras pudientes, bien acomodadas, más de una vez habría andado Gerardo esposado con dos sonetos con estrambote, carretera adelante.

(...) Lo peor del caso es que este tal anarquista literario es catedrático, y tenemos que entregar a nuestros hijos a un hombre que ha escrito versos como Amor amor obesidad hermana

¡Vergonzoso! Lo que pasa en España no pasa en ninguna parte. Porque, en efecto, igual que la mozuela descarriada, que después de haber andado hasta las tres de la madrugada de parranda, en los dancings -el descote hasta aquí- con unos y otros (esos unos y otros son, en este caso, los ultraístas, los superrealistas, los creacionistas y otras gentes de mal vivir poético), a la mañana siguiente se prende su mantilla, y con su traje bien cerrado va con su madre a misa de nueve, como si tal cosa, Gerardo, después de apedrearle las puertas a la Academia, todas las mañanas deja su manual de espumas, empuña el de retórica y poética, y encaramado en su tarima profesoral, inicia su lección:

-Hay varias clases de endecasílabos. El anapéstico...

(...) ¿Transfuga? ¿Tornadizo, de Max Jacob a Horacio, del ultimismo a la escuela sevillana? ¿Vacilante? ¿Desorientado?

No; fiel devoto de la señora que a todos nos entiende y a todos nos perdona. De una Nuestra Señora de la Poesía, que tiene un manto azul anchísimo, cuajado de estrellas de oro como en Zurbarán, y que alzando los brazos crea bajo sus pliegues un cobijo para todos -el poeta de ayer, y el de hoy- todos iguales, en su mucho o en su poco.

$\mathrm{Y}$ ante esta imagen, que a ninguna alma pura rechaza, Gerardo se hinoja y reza en décimas calderonianas. (27-28)

Puede citarse también la colaboración de Ricardo Gullón al homenaje que la revista alicantina Verbo tributó a Gerardo Diego en 1950:

Ahí sigue, enhiesta y atrayente la bandera de la libertad poética. A quien abomine los poemas creacionistas, preguntémosle, si cree, de verdad, que sin esa vertiente de su espíritu la poesía de Gerardo Diego sería tan incitante y tan bella como es. Y a 
los obsesos de lo nuevo, mostraremos simplemente las aladas cumbres de Ángeles de Compostela, y digan dónde y cómo la sujeción a la norma cercenó el ágil vuelo de la creación (21).

Es más, en su opinión, Gerardo Diego al aceptar esa duplicidad "ofrece el más patente testimonio de su sinceridad" (19). Con todo, el planteamiento de Gullón sigue siendo heredero de la estética neorromántica, sigue siendo un planteamiento de síntesis, conciliador, aunque ahora, al filo de la siguiente década, no necesite supeditar la vanguardia a la tradición. La rémora clasicista, que soportó el neorromanticismo en su origen y que Dámaso Alonso o González de Lama ponen de manifiesto, ha desaparecido ya en buena parte. Solo prevalece porque es uno de los términos en liza. Gullón usa el tópico tradición y vanguardia desposeído por fin de algunos condicionantes que contribuyeron a su gestación. Así lo utilizarán después otros muchos críticos hasta hoy. De aquí arranca un posible seguimiento de este tópico en la crítica literaria más reciente.

\section{CLASICISMO Y ROMANTICISMO: VICENTE ALEIXANDRE}

En los años cuarenta, Ricardo Gullón (1946) y Antonio González de Lama (1944 y 1947) leyeron la trayectoria poética de Vicente Aleixandre a partir de la dialéctica clasicismo / romanticismo. La poesía aleixandrina estaría en su opinión presidida por impulsos de índole romántica, refrenados, compensados, equilibrados, conforme el poeta va avanzando hacia su madurez, por fuerzas de origen clásico. Sombra del paraíso es la muestra más perfecta de ese equilibrio. Los libros precedentes se inclinaban por uno u otro de estos términos sin conseguir aunarlos:

Si Ámbito es clásico, y Espadas como labios es romántico, y La destrucción o el amor romántico represado, Sombra del paraíso está en la misma línea de La destrucción o el amor, pero más contenido aún, menos arrebatado. Y más perfecto, más acabado, más afilado. Sin la frialdad lapidaria del primer libro, sino con una perfección más conmovida, más agitada por un violento hervor que se alisa y remansa en la tersura resplandeciente de la forma. Es difícil alcanzar una nitidez tan esplendorosa sin perder un ápice de pasión, de fuerza, de humanidad vibrante y tremante (González de Lama, "Sombra del paraíso").

Pero hay otra oposición, oscuridad / luz, que gozó también de gran fortuna para definir la obra de Aleixandre, aunque tiene un significado más restringido, atañe solo a la vinculación con el surrealismo. Los elementos que, por ejemplo Ricardo Gullón o González de Lama, consideran desechables en este movimiento -prácticamente todos, a excepción de la rehumanización- los presentan siempre con vocablos pertenecientes al campo semántico de la oscuridad. La luz, por el contrario, es el final del camino, el punto culminante de una trayectoria, que con Sombra del paraíso ha sabido filtrar lo mejor del surrealismo -humanidad-y lo mejor del arte puro -la perfección formal-, 
para alcanzar así "la cima de la poesía española actual” (González de Lama, "Sombra del paraíso") ${ }^{15}$.

Casi todas las reseñas que aparecieron en los años cuarenta sobre Sombra del paraíso aluden a esa síntesis de lo clásico y lo romántico ${ }^{16}$. Pero sirva como muestra la publicada por Dámaso Alonso dos meses después de la de González de Lama, sobre todo porque es muy llamativa la semejanza entre ambas. También Dámaso Alonso comienza diciendo que Sombra del paraíso es "una de las cimas de la poesía española contemporánea" ("Visión paradisíaca" 7) -obsérvese incluso la coincidencia terminológica. También aprecia un importante componente romántico que, sin embargo, contiene, modera, una perfección formal emparentada con nuestros clásicos renacentistas y con Mallarmé:

Todos hemos llamado "romántica" a la poesía de Aleixandre. ¿Servirán todavía para algo estas palabras? Si para algo sirvieran, yo diría que Sombra del paraíso es poesía romántica aún por el empuje y la abundancia del manantial, por el anhelo total que la inspira. Mas también hay contradictorios misterios en los caminos de la belleza. Libérrimo sigue siendo el verso, pero ¡cuán bellamente ha fraguado en cada una de sus unidades! El mundo en fusión ha ido a aquietarse en expresiones que, palpitantes aún, tienen ya la perennidad de los mármoles más bellos. ¡Quién lo pensaría del autor de Espadas como labios! Sombra del paraíso ha alcanzado el límite de la hermosura posible en la palabra humana, como cuando más se haya rozado tal meta en el esfuerzo del Renacimiento, o en el de los neoclásicos, o en el del Parnaso, o en la línea que lleva a Mallarmé. ¡Bella piedra deslumbradora, bella, abrasada y fría, como tallada por un dios esta Sombra del paraíso, en la que Vicente Aleixandre, una triste tarde del mundo, se encontró definitivamente con la belleza! ("Visión paradisíaca" 7).

Y, además, aunque no menciona el surrealismo, también define la evolución de Aleixandre como un proceso que va "desde lo turbio hasta la más lavada limpidez":

Primero fue confusa, veteada de agrios o de dulcísimos, sin selección de materia, abrasadoramente, entusiasta o duramente sarcástica en Espadas como labios; luego se limpió de mucha ganga sobrepuesta, difuminó o eliminó las excrecencias sarcásticas, creció en la línea del amor y del fuego, fraguó en el sentido de la fuerza y la universalidad, llegando tal vez al máximo de su poder, en La destrucción o el amor, Y, en fin, ahora, en Sombra del paraíso, sin perder la vertiginosa altura y la grandeza,

15 Dice Gullón: "Ya señalé anteriormente que en Sombra del paraíso supera Aleixandre la desesperación, como deja atrás también su fase de oscuridad: el mundo cruelísimo y revuelto de Pasión de la tierra fue ordenado y clarificado..." ("Los poetas de Adonis" 131). Y González de Lama es de la misma opinión: "En Pasión de la tierra está, sí, el punto de arranque; pero en la poesía posterior hay más, mucho más de lo que este libro primordial apuntaba. "El camino hacia la luz" estaba aún sin descubrir; hoy el poeta ha caminado por él hasta la cima luminosa" ("Pasión de la tierra").

16 Las he analizado en Vanguardias y crítica literaria en los años cuarenta (101-103) y en La "Quinta del 42" y las vanguardias (23-24). 
se ha acelerado aún el proceso de eliminación, y el resultado ha sido un libro nítido, de limpieza original ("Visión paradisíaca" 7).

En cuanto a esta última oposición, Oscuridad / Luz, la emplearán igualmente otros críticos como R. Benítez Clarós, para quien "la diafanidad lógica” constituye la más importante cualidad de Sombra del paraíso en relación con poemarios anteriores (269). Lo mismo dirán, aunque ya en 1950, Leopoldo de Luis ${ }^{17}$ e Ildefonso Manuel Gil ${ }^{18}$, al ocuparse de Ámbito y Mundo a solas.

Por otra parte, Ventura Doreste, en un artículo titulado significativamente "La unidad poética de Aleixandre" (1950), señala que Ámbito es anticipo tanto de "los libros superrealistas" como de Sombra del paraíso, es decir, de "la atracción inevitable hacia el caos" y del "universo luminoso" (7). No parece, por tanto, que Doreste esté hablando de un proceso evolutivo en el que el caos y la oscuridad surrealistas hayan ido desapareciendo de forma gradual en favor de la luz paradisíaca, sino de dos líneas que discurren paralelas desde los comienzos y que, por ello, constituyen "la unidad poética de Aleixandre". Doreste utiliza, además, el fuego como símbolo del impulso unificador que genera toda la obra aleixandrina ${ }^{19}$. Habría, pues, que añadir la simbología del fuego a las empleadas -Clasicismo / Romanticismo, Oscuridad / Luz- para definir la poesía de Aleixandre. En este caso, se trata de un emblema de cohesión: no hay dos etapas o dos semblantes diferenciados en nuestro poeta sino un único ímpetu creador. Este planteamiento resulta novedoso al tenor del acuerdo general que por estos años existe en la crítica respecto a la división en dos etapas de la poesía aleixandrina: la surrealista, antes de la guerra, y la neorromántica, inmediatamente después.

Con esta nueva perspectiva lo que se sanciona finalmente es esa ya tópica concepción de la generación del 27, atraída igualmente por la tradición y la vanguardia. Esta concepción tiene su origen en el modelo neorromántico, empeñado en considerar la producción de posguerra más tradicional, menos arriesgada y, por tanto, superadora de los ideales vanguardistas anteriores. Después del inflexible orden garcilasista, un leve soplo de libertad quiso colarse en nuestras letras y lo hizo pagando el precio de la

17 Según Leopoldo de Luis, en Pasión de la tierra, Espadas como labios y La destrucción o el amor "el poeta (...) ha creado un mundo extraordinario, mágico, caótico, en el que apasionadamente intervienen las fuerzas vitales en una concepción unitaria y cósmica. Ha empleado para ello un material onírico y peculiarmente surrealista. Luego se ha clarificado, ordenado todo ese mundo, y ha creado la prodigiosa visión de Sombra del paraíso" (2).

18 "Cuando en 1945 apareció Sombra del paraíso, todos tuvimos la impresión de que en el reducido ámbito de nuestra poesía actual se había producido un acontecimiento de primera magnitud. En aquellos magníficos poemas, Aleixandre parecía abandonar sus anteriores nebulosas - ¿atormentadas?, ¿frías?- y se adentraba en los caminos abiertos y luminosos de una difícil y bella claridad poética. Lo cual no nos sorprendió a cuantos pensábamos que el surrealismo de sus libros anteriores era ya, por muchas razones, insostenible" (587).

19 "Sí, Ámbito es un libro contenido, pero en casi todos sus versos se está anunciando la ignición que siempre define la poesía total de Aleixandre" (7). 
constante conciliación: lo neorromántico es también clásico, lo vanguardista no resulta peligroso porque, además de pertenecer al pasado, ha sido solo una valiosa contribución, una estación obligada hacia la conversión final-siempre de signo tradicional y clásico. Desde aquí, no parece difícil dar un paso más para unificar vanguardia y tradición, tal como hace Doreste en 1950, sobre todo cuando el componente vanguardista ya había sido despojado por críticos como González de Lama o Dámaso Alonso de su faz más temible, más revolucionaria, y además ambos habían esbozado esa posibilidad de unión a propósito de Gerardo Diego.

Los distintos ensayos que Dámaso Alonso fue publicando sobre la poesía aleixandrina desde 1932, cuando se ocupó de Espadas como labios, son fundamentales al respecto. Sin ellos difícilmente se habría llegado a la unidad planteada por Doreste. En el artículo del año 32, Dámaso Alonso habla de una corriente neorromántica general -"Hiperrealismo"de la que el surrealismo francés sería solo un subgrupo (286). Su objetivo está claro: negar el influjo francés sobre los poetas surrealistas españoles. Por otra parte, duda de la existencia de un automatismo puro. En su opinión, siempre hay una posterior "fase selectiva" (288). Y Aleixandre no es en este sentido una excepción. Tres años después, y a propósito de La destrucción o el amor, volverá a insistir en este hecho:

La poesía de Aleixandre, como toda aquella parte de la moderna que está más o menos emparentada con el surréalisme francés y su pretendido automatismo, vuelve por fuerza a buscar el descansadero de la forma. Entiéndase bien: de una forma que, repito, nada tiene que ver con la forma clásica, sino de una forma vital, individual e individualizante, necesaria para hacer resaltar superficialmente la profunda unidad del poema ("La destrucción o el amor" 303).

Concluye entonces que no es correcta la traducción española del término surréalisme porque con ella se denomina una modalidad de ese neorromanticismo general o hiperrealismo que es completamente independiente de su homóloga francesa. Además, la escritura automática es una utopía. Dámaso Alonso define así los pilares de futuros acercamientos al tema: no se trata de surrealismo sino de neorromanticismo y no hay escritura automática. En cuanto a esta última cuestión, es muy importante constatar que esa ausencia de automatismo atañe tanto a la variante española como a la francesa. Según Dámaso Alonso, no es una característica exclusiva de España, como lo sería para la crítica posterior.

Todavía en los años treinta, Pedro Salinas utilizará todos estos conceptos de forma muy particular: hablará de neorromanticismo en lugar de surrealismo, pero ahora para el caso concreto de Aleixandre, y justificará este juicio por la falta de escritura automática. Lo que ya apuntaba en los textos de Dámaso Alonso aparece ahora perfectamente formulado en el de Salinas:

Hasta ahora en este somero repaso de temas, nos hemos tropezado con la visión del mundo y de la sensibilidad romántica frecuentemente. Cabría calificar a Aleixandre como poeta inscrito dentro del círculo neorromántico, cada día más poderoso, de la poesía moderna. Pero si volvemos ahora a estudiar su lenguaje, su expresión poética, nos hallaremos en tangencia con otra escuela muy de hoy: el superrealismo. No hay 
en eso contradicción ni mera superposición accidental. En cierto modo, el superrealismo, o las escuelas afines que desde hace veinte años bullen en las letras, podrían tomarse como una consecuencia extrema, desmesurada de lo romántico. Así como la razón era la enemiga de los románticos, la gran heroína clásica con que luchaban, la lógica era la bestia negra del superrealismo, cuyo esfuerzo se concentra en sofocarla, en ensordecer ante su voz y atender a otras oscuras y profundas. Aleixandre no es un poeta superrealista. Ha pasado junto a esta escuela, y en su lengua poética adopta decididamente y con una brillantez y acierto no superados en español, ni acaso en otros idiomas, todas las libertades ofrecidas por esta escuela. Pero hay en su poesía una lógica interna que se soterra a veces, dando la impresión de incoherencia absoluta, aunque no puede engañar. La liberación de la lógica, el abandono del poeta al dictado de lo inconsciente, que existe sin duda en este libro a trechos, no pasa de un plano subordinado, no afecta a la génesis del poema, no es sistema. El poema es siempre fiel a su arranque, a su idea, a lo que vemos nacer, ya con el título muchas veces... Pero hay una impresión final unitaria del poema, y se percibe que a través de las licencias y escapadas de la lógica que el poeta se permite, la idea poética no deja de dominar el conjunto ("Vicente Aleixandre" 210).

Su postura es más intransigente que la de su compañero. Con él, surrealismo y neorromanticismo, que en Alonso eran conceptos perfectamente compatibles, se convierten en contrarios: Aleixandre es un neorromántico pero para no ser surrealista, es un neorromántico "por oposición a”. Y en el tema del automatismo también se da un paso más adelante: si para Dámaso éste era un imposible, para Salinas será un imposible en la poesía aleixandrina.

De las conjunciones de estos tres pilares básicos -neorromanticismo, surrealismo, automatismo - arrancan las distintas teorías que la crítica ha venido sosteniendo sobre el tema desde entonces. Durante los años cuarenta domina la posición de Salinas, que será desarrollada por críticos como González de Lama o Ricardo Gullón con la fórmula siguiente: frente a la luz neorromántica -léase diafanidad lógica, cuidado de la forma, etc.-, la oscuridad surrealista-léase escritura automática. En este período, Dámaso Alonso es partícipe de esta tesis -así lo demuestra su artículo sobre Sombra del paraíso-, que, si bien se mira, no resulta tan contraria a la que él formula en los años treinta. De hecho, en ella se halla el origen de esta otra. Dámaso Alonso no ha tenido que hacer ningún esfuerzo para aceptarla, porque a la postre se trata de seguir hablando de neorromanticismo y no de surrealismo, y de negar la escritura automática.

Pero el término surrealismo termina por imponerse. No se olvide que los franceses, al constituirse en un movimiento organizado de amplísima repercusión internacional, dieron, por así decirlo, “el nombre a la cosa”. En 1949, Dámaso Alonso, no sin hacer patente su desacuerdo y su queja, decide resignadamente aceptarlo para el caso de España. Es entonces cuando por primera vez hablará de "surrealismo español", aunque lo hará en una nota a pie de página y de forma marginal al tema que está tratando:

Digo "lamentablemente" porque da pena emplear un extranjerismo (que en seguida sugiere dónde se debió originar el movimiento) cuando creo que el llamado "surrealismo" español tiene raíces autóctonas, cuyo desarrollo posterior se ve favorecido por el 
movimiento francés. Lo mismo ocurre ahora con esa peste de "existencialismo". (...) Por lo visto, españoles e hispanoamericanos tenemos la firme creencia de que siempre es menester que alguien nos colonice: ¡estamos aviados! ("Poesía arraigada" 707).

Un año después, en su discurso de contestación a Vicente Aleixandre con motivo del ingreso de éste en la Real Academia Española, volverá a mostrar no sin disgusto su consentimiento:

Me fastidia tener que emplear la palabra superrealismo: ya no hay más remedio que hacerlo. Vamos interpretando la historia de España y de su literatura siempre a la zaga de algo que venga de fuera. Cuando lo nuestro no se conforma bien con el nombre extraño lo metemos de un empujón en el molde que nos llega. (...) Así se echó mano del surréalisme francés, y se tradujo la palabra, para que fuera marbete de cosas españolas. Porque la imagen onírica, característica del surréalisme, existe ya, claro que con rasgos muy peculiares, en el Lorca de las Canciones escritas de 1921 a 1924, y el libro de poemas en prosa Pasión de la tierra, de Aleixandre, publicado también tardíamente (en Méjico -hay una segunda edición española), fue escrito cuando el poeta no tenía idea de la escuela de Breton, Aragon, etcétera; ni hay conexión transmitiva tampoco entre el superrealismo francés y Sobre los ángeles, de Alberti. La poesía francesa y la española recogieron, pues, independientemente, cosas que estaban en el aire. Después se produce un contacto de la poesía española con la francesa superrealista y hay ya influjo de ésta ("Aleixandre en la Academia” 326).

Por otra parte, fiel a sus convicciones iniciales, no solo afirma el carácter selectivo y elaborado de las imágenes aleixandrinas sino que ni siquiera se plantea ni menciona la cuestión del automatismo. Dejaba así la puerta abierta para que futuros investigadores hablasen de una modalidad surrealista española cuya principal peculiaridad radica en la ausencia de escritura automática, tal como hará Paul Ilie en 1968.

Pero Ilie contó con otros precedentes: por ejemplo, los de Carlos Bousoño y Manuel Durán. Bousoño, cuyo libro sobre Aleixandre se publicó en 1950, poco después del discurso de Dámaso Alonso, sostiene las mismas tesis que el crítico madrileño había venido formulando desde 1932. Según Bousoño, "la escuela superrealista española (...) nació con independencia de la escuela francesa de análoga tendencia, y sólo después, en marcha ya el movimiento hispano, puede hablarse de contactos entre una y otra" ( $L a$ poesía de Vicente Aleixandre 225-226). Aleixandre, cuyo período surrealista se limita a Pasión de la tierra, recibió el influjo no del movimiento francés sino de la "tradición visionaria española" y de la lectura de Freud, Rimbaud y Joyce. Después, gracias a una "sucesiva depuración” alcanzó la “clásica limpidez de Sombra del paraíso y de los libros subsiguientes” (226). Por otra parte, y siempre fiel a su maestro Dámaso Alonso, Bousoño dice que, aunque en la teoría Breton hubiese hablado de "automatismo psíquico puro", "en la práctica el superrealismo puro nunca existió". Y añade: "en España, desde luego, ningún poeta en sus versos parece haber pretendido aquella extremosidad" (225). Y Manuel Durán, en el primer estudio monográfico sobre el tema (1950), desarrolla estas tesis con una distinción muy particular entre escritura automática y poema surrealista, entre poesía surrealista (en la que sí hay control lógico) y "surrealismo a secas": 
El relato de un sueño y la escritura automática (...) nos ponen en contacto con el subconsciente del que los relata o escribe, y ello en forma auténtica y válida. El poema no. Por mucho que se parezca al texto surrealista, el poema denota un esfuerzo consciente -por mínimo que sea- de ordenación, de sustitución de unas palabras por otras, en un intento deliberado de producir un aspecto artístico. El poema surrealista utiliza los materiales que le proporciona el subconsciente para elaborarlos con vistas a un fin estético.

Basta comparar los más bellos poemas surrealistas de Paul Eluard con un texto automático cualquiera para comprender el abismo estético que separa la poesía surrealista del surrealismo como expresión a secas. El material empleado es casi el mismo: frases a veces inconexas e incoherentes, desprecio por la puntuación y la gramática, sinuosidad de la expresión que se mueve a un ritmo enigmático e imprevisible. Pero el poema surrealista, mediante un esfuerzo de selección y de sustitución análogo al de toda obra artística, se ha convertido en poesía, mientras que el texto sigue siendo amarga "prosa" - prosa, por otra parte, sumamente aburrida (17-18).

Desde las teorías de Ortega sobre la deshumanización, de grandísimo impacto en la tradición crítica de este siglo, ni los poetas ni los críticos se resignan a perder el alto rango que éstas les conferían, el inmenso grado de protagonismo que les suponen, la condición de arte, de especialización, de conciencia, de técnica, etc. ¿Cómo se habrían entonces de enfrentar al movimiento surrealista, destructor del mito del poeta artífice, potenciador de aquellos ámbitos sobre los cuales el ser humano no puede ejercer un dominio consciente? De este combate de fuerzas contrarias surgen argumentaciones como la de Dámaso Alonso, o la de Durán, que son, en realidad, soluciones de compromiso, muy frecuentes, como ya sabemos, en nuestra Estilística: nunca un formalismo radical, pero tampoco un contenidismo exacerbado. Por otra parte, la tesis de un surrealismo español sin escritura automática iba tomando cuerpo, desde el momento en que Dámaso Alonso apuntó la posibilidad para el caso de Aleixandre ${ }^{20}$.

Evidentemente, de las teorías de Dámaso Alonso deriva la conciliación del caos y la luz, que planteaba Doreste. Para Dámaso Alonso, en efecto, no hay más remedio que

20 El ensayo de Durán resulta modélico al respecto. Después de haber negado la posibilidad de automatismo en los poemas surrealistas, de haber considerado este hecho un rasgo típico de toda la lírica surreal, nos sorprende afirmando la peculiaridad no automática de la variante española. Entre las características del "desarrollo de las tendencias surrealistas en España", señala que "cuando consigue imponerse, raras veces lo hace en la forma pura de la escritura automática" (39), con las excepciones de Picasso y José María Hinojosa, los dos únicos casos de "surrealismo ortodoxo y total" (59). Si la poesía surrealista no es automática, ¿qué sentido tiene establecer un subgrupo de la corriente general en razón de ese rasgo?, ¿por qué hablar de ortodoxia y heterodoxia? En el trabajo de Durán, primera -insisto-monografía sobre esta controvertida cuestión, conviven y se entrecruzan las teorías que hasta la fecha la crítica española había ido elaborando: la de Dámaso Alonso y sus reticencias sobre el automatismo, la de Salinas y sus reticencias sobre el automatismo para el caso de España, la de Dámaso y su resignada aceptación del termino surréalisme, etc. 
admitir el surrealismo aleixandrino, pero un surrealismo que él ha tenido buen cuidado de pulir hasta hacerlo compatible con sus planteamientos estéticos -un surrealismo que presta gran atención a la forma, que no pierde nunca la conciencia, etc. Desprovisto de sus caracteres más subversivos, puede por tanto ser esgrimido como una cualidad de Aleixandre no solo desde sus libros iniciales -tesis que dominó en una buena parte de la década- sino a lo largo de toda su carrera literaria.

\section{LORCA: UN SURREALISMO NEOPOPULARISTA}

El tópico de la tradición y la vanguardia sigue un proceso de creación a lo largo de los años cuarenta que es, en todos los casos, el mismo. En primer lugar, se apuesta por la faceta tradicional del autor en cuestión. Y después se lee también en términos tradicionales la vertiente vanguardista.

En lo que concierne a la poesía lorquiana, el proceso lo inicia de nuevo Dámaso Alonso en 1944 con un artículo titulado significativamente "Federico García Lorca y la expresión de lo español". Españolidad de signo "populista" y "folklorista" es, según Sultana Wahnón, el carácter más sobresaliente que Dámaso Alonso otorga al poeta granadino. Pero, como Dámaso Alonso orientó esa presunta "españolidad" sobre todo por derroteros políticos, Wahnón cree que no consiguió una total recuperación de Lorca, al estilo de la llevada a cabo por Dionisio Ridruejo con Antonio Machado. En ese intento de recuperación, la poesía vanguardista, deshumanizada, surrealista quedaba sin explicar. Hasta que Díaz-Plaja proponga la conciliación de vanguardia y tradición en su libro de 1948, Federico García Lorca. Estudio crítico, no tendrá lugar la recuperación definitiva, la aceptación final. Con certero juicio, Wahnón apunta que el "clasicismo de equilibrio", la conciliación de tradición y vanguardia propugnada por Díaz-Plaja, se resuelve en la imagen menos subversiva, menos vanguardista de Lorca ("García Lorca y la estética de posguerra" 12).

Sin embargo, yo no creo que el intento de Dámaso Alonso resultase infructuoso. Para poder hablar de tradición y vanguardia en un poeta determinado, tiene que haberse establecido previamente y sin lugar a discusiones su tradicionalidad. En este sentido, el trabajo de Dámaso Alonso allanaba mucho el camino. Además, dos años antes de la publicación del libro de Guillermo Díaz Plaja, Charles David Ley, desde las páginas de Garcilaso, traspasaba esa tradicionalidad de perfil populista a la vertiente vanguardista, es decir, leía en clave neopopular el surrealismo lorquiano:

La razón por la cual el "Romancero Gitano" puede ser el único libro en el mundo que después quede de la época surrealista, es que los símbolos ahí no son los de la vida particular del autor, sino antiguas imágenes de la tradición andaluza, de las cuales quienquiera que sea puede enterarse ("Prólogo. Los poetas de Garcilaso").

Ésta es la prueba definitiva que Ley aporta para aminorar el impacto de la vanguardia, y, en contrapartida, tal como hizo Dámaso Alonso, proclamar la tradicionalidad del fenómeno poético aun en sus experimentos más antitradicionales y subversivos. 
Dámaso Alonso y Charles David Ley preparan así el terreno para que en 1948 Guillermo Díaz Plaja pueda por fin, una vez que la vanguardia ha perdido su fisonomía más revolucionaria, hablar de síntesis entre tradición y modernidad como rasgo definidor de la poesía lorquiana:

La obra de Federico García Lorca se señala entre la de sus compañeros por la inteligencia y armónica fusión de los elementos tradicionales y los restauradores, por la espléndida aleación de un sabor clásico y una renovadora y juvenil curiosidad (14).

\section{CONCLUSIÓN}

Culmina así la conversión de tres miembros muy destacados de la generación del 27 -Gerardo Diego, Vicente Aleixandre y Federico García Lorca-a la estética neorromántica de posguerra, que siempre busca el equilibrio, bien para no chocar con los ideales clasicistas del garcilasismo o bien para absorber estos ideales una vez que ha alcanzado ella misma el rango de estética dominante. Gerardo Diego simplifica mucho las cosas porque presenta una abundante producción que, sin grandes dificultades, puede situarse en una línea tradicional. Solo hay que interpretar también en términos tradicionales su poesía creacionista. Igual ocurre con el surrealismo lorquiano, que se lee desde una perspectiva neopopularista. El caso de Aleixandre es, sin embargo, más complicado. No es fácil hallar en la producción del sevillano algún poema de aspecto resueltamente tradicional. ¿Cómo recuperarlo entonces? Hay dos posibilidades, que arrancan de Pedro Salinas y Dámaso Alonso. Salinas se limita a negar el surrealismo. Prefiere calificar de neorromántica la poesía de Aleixandre, porque en ella no hay automatismo. Desarrolla así, y reelabora, las teorías de Dámaso Alonso sobre la existencia de un neorromanticismo general, del que el surrealismo sería solo una variante. Pero Dámaso Alonso pone también las bases para la posterior aceptación del surrealismo aleixandrino, después de haber suprimido sus aspectos más problemáticos: la escritura automática (está convencido de la imposibilidad de todo automatismo, de la existencia en todos los casos de un proceso consciente de selección). Pues bien, esta aceptación y la definitiva lectura de Aleixandre a partir del mito tradición / vanguardia llega con Ventura Doreste en 1950 y tendrá una gran repercusión en la crítica literaria, sobre todo tras la publicación de Historia del corazón, poemario que marca lo que algunos llamaron el «arrepentimiento», la «abjuración estética» de Aleixandre (Busuioceanu).

Una conclusión fundamental se obtiene, además, de todo esto: el papel de primer orden que Dámaso Alonso, como crítico, desempeñó en la creación y afianzamiento del tópico tradición versus vanguardia. En los tres casos analizados su intervención resulta decisiva. Consigue así que la faceta más heterodoxa de su generación sea aceptada, no parezca peligrosa para el conservadurismo estético y político de la primera posguerra. Por eso, cuando en 1948 publica ese ensayo ya emblemático, "Una generación poética (1920-1936)", insiste tanto en la ausencia de ruptura con lo anterior, en los esfuerzos que sus compañeros realizaron por recuperar la tradición poética española. 


\section{BIBLIOGRAFÍA}

Albi, José. "La introversión o el bonito juego de la vida". Verbo 14 (1949): 21.

Aleixandre, Vicente. Pasión de la tierra. México: Fábula, 1935. Madrid: Adonais, 1946.

Sombra del paraíso. Madrid: Adán, 1944.

Alonso, Dámaso. "Espadas como labios". Revista de Occidente XXXVIII/CXIV (1932): 323-333.

340 .

“La destrucción o el amor". Revista de Occidente XLVIII/CXLIV (1935): 331-

“Alondra de Gerardo Diego (Poesía de Verdad)". Escorial XI. 30 (1943): 119141.

"Federico García Lorca y la expresión de lo español”. Ensayos de poesía española. Madrid: Revista de Occidente, 1944. Poetas españoles contemporáneos. Madrid: Gredos, 1952. 271-280.

"Visión paradisíaca en la poesía de Aleixandre”. El Español 93 (1944): 7.

“Una generación poética (1920-1936)". Finisterre I/35 (1948): 193-220. Poetas

españoles contemporáneos. 167-192.

“Poesía arraigada”. Cuadernos Hispanoamericanos 9 (1949): 691-709.

332.

(1950). “Aleixandre en la Academia”. Poetas españoles contemporáneos. 318-

Benitez Clarós, Rafael. "Vicente Aleixandre y Sombra del paraíso". Cuadernos de Literatura Contemporánea III (1944): 261-273.

Bernal, José Luis. “La ejemplaridad vanguardista de Gerardo Diego". Treinta años de vanguardia española. Coord. Gabriele Morelli. Sevilla: El Carro de la Nieve, 1991. 121-135.

Bousoño, Carlos. La poesía de Vicente Aleixandre. Madrid: Insula, 1950.

"Un aspecto de Gerardo Diego: el simultaneísmo de su diversidad". Boletín de la Real Academia Española. LXVIII/CCXLIV (1988): 195-201.

Busuioceanu, Alejandro. "Vicente Aleixandre revela sus secretos". Insula 37 (1949): 8.

Cirre, José Francisco. Forma y Espiritu de una lírica española (1920-1935). México: Gráfica Panamericana, 1950.

Cossío, José María de. “La poesía de Gerardo Diego”. Escorial V/14 (1941): 44-451.

Díaz Plaja, Guillermo. Federico García Lorca. Estudio crítico. Buenos Aires: Guillermo Kraft, 1948.

Diego, Gerardo. "Intencionario". Grecia. XLVI (1920): 6-7.

"Poetas del norte: Miguel de Unamuno, José del Río Sáinz, Ramón de Basterra". Revista de Occidente. IV (1922): 128-132.

Soria. Valladolid: Libros para amigos. Santander, 1923. El Viento Sur, 1948.

Poesía española contemporánea. 1932 y1934. Andrés Soria Olmedo. Ed. Madrid:

Taurus, 1991.

Alondra de verdad. Madrid: Ediciones Escorial, 1941. 
Primera antología de sus versos. Madrid: Espasa Calpe, 1941.

"Vicente Aleixandre, académico de la Española". Revista Nacional de Educación 94 (1950): 73-75.

Doreste, Ventura. "La unidad poética de Aleixandre". Insula 50 (1950): 6.

Durán, Manuel. El superrealismo en la poesía española contemporánea. México: UNAM, 1950.

Espejo-Saavedra, Rafael. "Elementos tradicionales en la poesía ultraísta de Gerardo Diego". Anales de Literatura Española Contemporánea 7/2 (1982): 201-214.

Gaos, Vicente. Antología del grupo poético de 1927. Madrid: Cátedra, 1981.

Gil, Ildefonso Manuel. "Vanguardia y complemento de Sombra del paraíso en el último libro de V. Aleixandre”. Cuadernos Hispanoamericanos 15 (1950): 587-590.

González, Ángel. El grupo poético de 1927. Madrid: Taurus, 1978.

González de Lama, Antonio. "La nueva poesía de Dámaso Alonso". Espadaña 2 (1944). “Sombra del paraíso". Espadaña 3 (1944). “La poesía de Gerardo Diego". Espadaña 5 (1944). "Pasión de la tierra". Espadaña 25 (1947). “Soria de Gerardo Diego". Espadaña 41 (1949).

Gullón, Ricardo. “Los poetas de Adonais”. Proel 3 (1946): 127-138. “Gerardo de verdad”. Verbo 19-20 (1950): 19-21. “Homenaje a Jorge Guillén”. Insula 26 (1948).

Ilie, Paul. Los surrealistas españoles. Madrid: Taurus, 1968, 1982.

Ley, Charles David. "Prólogo. Los poetas de Garcilaso". Garcilaso 35-36 (1946).

Luis, Leopoldo de. "Actualidad de Ámbito. El primer libro de Aleixandre”. Insula 52 (1950): 2.

Navas Ocaña, María Isabel. Vanguardias y crítica literaria en los años cuarenta. El grupo de Escorial y la “Juventud Creadora". Almería: Servicio de Publicaciones de la Universidad de Almería, 1995.

La "Quinta del 42" y las vanguardias. Las revistas Corcel y Proel. Granada: Servicio de Publicaciones de la Universidad de Granada, 1996.

Espadaña y las vanguardias. Almería: Servicio de Publicaciones de la Universidad de Almería, 1997.

El movimiento postista. Teoría y crítica. Almería: Universidad de Almería, 1997.

Nora, Eugenio G. de. "La obra de Gerardo Diego a través de su primera "Antología"”. Cuadernos Hispanoamericanos 4 (1948): 135-149.

Presa González, Fernando. La revista Espadaña en la poesía española de posguerra. Madrid: Universidad Complutense, 1988.

Salinas, Pedro. "Vicente Aleixandre entre la destrucción o el amor", 1935. Literatura española. Siglo XX. Madrid: Alianza, 1970. 204-212.

“Gerardo de Diego". Proel 1 (1946): 27-28. 
Stefano, Gianfranco di. "Clasicismo y creacionismo en los Poemas adrede de Gerardo Diego". Prohemio 2-3 (1974): 253-270.

Wahnón, Sultana. “García Lorca y la estética de posguerra”. Insula 476-477 (1986): 12-13. Estética y crítica literarias en España (1940-1950). Granada: Universidad de Granada, 1988. 